\title{
Interleukin-15 increases calcineurin expression in 3T3-L1 cells: Possible involvement on in vivo adipocyte differentiation
}

\author{
VANESSA ALMENDRO ${ }^{1,2}$, GEMMA FUSTER ${ }^{1,2}$, ELISABET AMETLLER ${ }^{1,2}$, \\ PAOLA COSTELLI ${ }^{3}$, FEDERICA PILLA $^{3}$, SILVIA BUSQUETS ${ }^{1,2}$, MAITE FIGUERAS $^{1,2}$, \\ JOSEP M. ARGILÉS ${ }^{1,2}$ and FRANCISCO J. LOPEZ-SORIANO ${ }^{1,2}$ \\ ${ }^{1}$ Departament de Bioquímica i Biologia Molecular, Facultat de Biologia, \\ Universitat de Barcelona; ${ }^{2}$ Institut de Biomedicina de la Universitat de Barcelona, Barcelona, Spain; \\ ${ }^{3}$ Dipartimento di Medicina e Oncologia Sperimentale, Università di Torino, Torino, Italy
}

Received May 6, 2009; Accepted July 7, 2009

DOI: 10.3892/ijmm_00000252

\begin{abstract}
Different studies have revealed that the $\mathrm{Ca}^{2+}$ dependent serine/threonine phosphatase calcineurin is involved in the regulation of adipocyte differentiation. Calcineurin acts as a $\mathrm{Ca}^{2+}$-dependent molecular switch that negatively regulates the ability of 3T3-L1 cells to undergo adipocyte differentiation by preventing the expression of critical proadipogenic transcription factors. In this study we investigated the role of interleukin-15 (IL-15), a cytokine previously known to be involved in the control of fat accretion by adipose cells, in the differentiation of the 3T3-L1 preadipose cell line. We found that IL-15 is able to increase $\alpha$-calcineurin mRNA content in white adipose tissue of rats chronically treated with the cytokine and also in the 3T3-L1 preadipose cell line. Moreover, IL-15 promoted a decrease in both leptin mRNA expression and lipid accumulation, as estimated by Red Oil $\mathrm{O}$ staining. Cotreatment with IL-15 and FK506 (a calcineurin inhibitor) resulted in no changes in lipid content compared with the non-treated group. These data suggest that IL-15 directly inhibits adipogenesis, possibly by upregulating $\alpha$-calcineurin and preventing the induction of adipocyte differentiation.
\end{abstract}

\section{Introduction}

Adipocytes are highly specialized cells that play an important role in the regulation of energy homeostasis, insulin sensitivity, immunologic response and cardiovascular diseases $(1,2)$. Adipose tissue development involves both cellular hypertrophy (increase in cell size as a result of excess triacylglycerol accumulation) and hyperplasia (increase in cell number as a result of increased de novo adipocyte differentiation) (3). An

Correspondence to: Dr Francisco J. López-Soriano, Cancer Research Group, Departament de Bioquímica i Biologia Molecular, Facultat de Biologia, Universitat de Barcelona, Diagonal 645, 08028-Barcelona, Spain

E-mail: flopez@ub.edu

Key words: interleukin-15, calcineurin, adipocyte differentiation, leptin excessive increase in the adipocyte hyperplasia and/or hypertrophy can lead to an accumulation of adipose tissue and consequently, obesity. Obesity is a multifactorial disorder that is a risk factor for other diseases including insulin resistance, type-2-diabetes and cancer (4). For this reason, understanding the mechanisms that govern the regulation of differentiation and proliferation of adipose cells is of special interest because of the increasing incidence of obesity in developing countries (5).

Different studies have demonstrated that increases in intracellular $\mathrm{Ca}^{2+}$ concentration during the early phases of adipogenesis, both in human and 3T3-L1 adipocytes, causes a strong inhibition of the cellular differentiation process (6). This effect seems to be regulated by calcineurin, a $\mathrm{Ca}^{2+}$ dependent serine/threonine phosphatase that is known to be a critical downstream effector of the $\mathrm{Ca}^{2+}$ signal, and that mediates the $\mathrm{Ca}^{2+}$-dependent inhibition of adipocyte differentiation in 3T3-L1 cells (7). It exists as a heterodimer formed by two subunits, calcineurin $\mathrm{A}$, which has catalytic properties, and calcineurin B, with regulatory functions (8). Following an increase in intracellular $\mathrm{Ca}^{2+}$ concentrations, activated calcineurin binds and dephosphorylates the cytoplasm members of the nuclear factor of activated T cells (NFAT) family, unmasking two nuclear localization sequences and thus allowing their translocation to the nucleus, where they bind DNA and interact with other transcription factors such as AP-1 (9).

It was demonstrated that specific calcineurin inhibitors (like cyclosporin A and FK506) overcame the anti-adipogenic effect of $\mathrm{Ca}^{2+}$ ionophore on the differentiation of 3T3-L1 preadipocytes, and that the expression of a constitutive active calcineurin mutant inhibits adipocyte differentiation by preventing the expression of key transcription factors of adipocyte differentiation, peroxisome proliferation-activated receptor $\gamma(\mathrm{PPAR} \gamma)$ and CCAAT/ enhancer-binding protein $\alpha$ $(\mathrm{C} / \mathrm{EBP} \alpha)(7)$. In fact, previous studies suggest that NFAT proteins present in $3 \mathrm{~T} 3-\mathrm{L} 1$ preadipocytes are implicated in the regulation of adipocyte differentiation and function (10). Expression of an active NFAT mutant that constitutively localizes to the nucleus inhibits the capacity of 3T3-L1 cells to undergo adipocyte differentiation by inducing a state of cellular transformation (11). Thus, the factors that regulate either $\mathrm{Ca}^{2+}$ signalling, calcineurin activity or NFAT activation, 
could be of a great interest to block the process of adipocyte differentiation and/or proliferation. However, to date there are no mechanisms implicated in the regulation of calcineurin signalling on adipose cells.

Of particular interest to the current study is the implication of interleukin-15 (IL-15) in the regulation of adipocyte differentiation and proliferation. IL-15 is a multifunctional cytokine firstly identified in the supernatant of the monkey epithelial cell line CV-1/EBNA which induces a broad range of effects inside the immune system $(12,13)$. IL-15 mediates its functions through the $\beta$ and $\gamma$ chains of the IL- 2 receptor (14), and the expression of its gene has been detected in the placenta, skeletal muscle, kidney, lung and heart (12). We previously demonstrated that this cytokine can act as an autocrine anabolic factor for skeletal muscle (15). In the course of in vivo studies regarding the effects of IL-15 on skeletal muscle, a $33 \%$ decrease in white adipose tissue (WAT) mass was observed in rats, with no changes in food intake $(15,16)$. In another study using obese rodent models, a correlation was found between the sensitivity to the fat-inhibiting effects of IL-15 and the mRNA expression of key signalling subunits of the IL-15 receptor in WAT (17), suggesting that IL-15 has a direct effect on this tissue. Additionally, Quinn et al (18) reported a direct inhibition of adipogenesis in 3T3-L1 cells, which is linked to a decrease in PPAR $\gamma 2$, confirming the direct action of the cytokine on WAT. Bearing all this in mind, the aim of the present study was to analyze the effects of IL-15 on adipocyte differentiation and proliferation, relating to calcineurin mRNA expression under IL-15 treatment.

\section{Materials and methods}

Animals and treatments. Male Wistar rats (Interfauna, Barcelona, Spain), weighing 120-140 g, were used. The animals were maintained at $22 \pm 2^{\circ} \mathrm{C}$ with a regular light-dark cycle (light on from 08:00 a.m. to 08:00 p.m.) and had free access to food and water. The diet (B.K. Universal G.J./S.L., Sant Vicenç del Horts, Barcelona, Spain) consisted of $45.5-48.5 \%$ carbohydrate (3.5\% absorbable glucose, $42-45 \%$ starch), $18.5 \%$ protein and $3.1 \%$ fat (the residue was non digestible material). IL-15 was obtained from Immunex (Seattle, WA, USA). It was dissolved in sterile physiological saline and administered daily s.c. $(100 \mu \mathrm{g} / \mathrm{kg} \mathrm{bw})$. Control animals received the same volume of vehicle. The animals were sacrificed after 7 days of cytokine administration. Food and water intake and body weight were measured daily. After 7 days of IL-15 treatment, animals were weighed and anaesthetized with an i.p. injection of ketamine/xylazine mixture (3:1) (Imalgene ${ }^{\circledR}$ and Rompun ${ }^{\circledR}$ respectively). Blood was collected from the abdominal aorta into heparinized tubes and centrifuged $(3,500 \mathrm{x} \mathrm{g}, 10 \mathrm{~min}$, $4^{\circ} \mathrm{C}$ ) to obtain plasma. Dorsal WAT was rapidly excised, weighed, and frozen in liquid nitrogen. All animal manipulations were made in accordance with the European Community guidelines for the use of laboratory animals.

Cell culture and adipocyte differentiation. 3T3-L1 preadipocytes (ATCC) were cultured in a growth medium of Dulbecco's modified Eagle's medium (DMEM) with high glucose (Invitrogen) supplemented with $10 \%(\mathrm{v} / \mathrm{v})$ fetal calf serum, 25 mM HEPES pH 7.0, 1,000 units/ml penicillin and strepto- mycin each and $25 \mu \mathrm{g} / \mathrm{ml}$ fungizone (BioWhittaker). To induce adipocyte differentiation, cells were grown until 2 days postconfluence and then treated for 2 days with differentiation medium of DMEM with high glucose supplemented with $10 \%$ (v/v) fetal bovine serum (Invitrogen), $25 \mathrm{mM}$ HEPES $\mathrm{pH} 7.0,1000$ units/ml penicillin and streptomycin each and $25 \mu \mathrm{g} / \mathrm{ml}$ fungizone, plus MDI (0.5 mM isobutylmethylxanthine, $0.25 \mu \mathrm{M}$ dexamethasone and $5 \mu \mathrm{g} / \mathrm{ml}$ insulin, Sigma). At day 2 cells were re-fed with differentiation medium that only contained $5 \mu \mathrm{g} / \mathrm{ml}$ insulin instead of MDI, and every 2 days thereafter with differentiation medium alone. For the short-term study of the effects of the cytokine on adipogenesis, undifferentiated 3T3-L1 fibroblast cells were treated with $10 \mathrm{ng} / \mathrm{ml} \mathrm{IL-15}$ in sterile PBS (Promega) during $48 \mathrm{~h}$ after (referred herafter preadipocytes in short-term study) and before inducing differentiation (referred hereafter as differentiating adipocytes), or with vehicle solution. For the long-term study, 3T3-L1 cells were treated with either $10 \mathrm{ng} / \mathrm{ml} \mathrm{IL-15}$ (Peprotech) or PBS for 7 days before inducing differentiation (referred hereafter as pre-adipocytes in long-term study) and for 7 days after inducing differentiation (referred hereafter as 7 d-adipocytes). All experimental groups were analyzed at the end of the treatment.

The calcineurin inhibition studies were carried out with $7 \mathrm{~d}$-adipocytes which were divided into four groups. Two groups received either $10 \mathrm{ng} / \mathrm{ml}$ IL-15 or PBS for 7 days. The third group received the calcineurin inhibitor FK506 (Sigma) at $5 \mathrm{ng} / \mathrm{ml}$ for the first 4 days after inducing differentiation, and the fourth group received $10 \mathrm{ng} / \mathrm{ml} \mathrm{IL-15}$ for 7 days and also $5 \mathrm{ng} / \mathrm{ml} \mathrm{FK506}$ for the 4 days indicated. All experimental groups were analyzed at the end of the treatment. After the different treatments, cells were fixed with paraformaldehyde $3 \%$ and stained with the lipophylic dye Oil Red O (Sigma) dissolved in isopropanol, as previously described (18). Stained cells were visualized by bright field microscopy, measures of lipid content diameters were taken and then cells were photographed.

Reverse transcription-polymerase chain reaction. Total RNA was extracted from WAT or for different cultured cells with the TriPure reagent (Roche), and quantified spectrophotometrically. RNA integrity was checked by electrophoresis on $1.2 \%$ agarose gel, containing $10 \% \quad 0.2 \mathrm{M}$ MOPS and $18 \%$ formaldehyde.

$\alpha$-calcineurin and leptin mRNA levels were analyzed by semiquantitative reverse-transcription polymerase chain reaction (RT-PCR) using the Kit Ready-to-Go RT-PCR Beads (Amersham). Aliquots of total RNA (0.5 $\mu \mathrm{g}$ for calcineurin and $0.2 \mu \mathrm{g}$ for leptin) were added to an RT-PCR reaction mixture containing PCR buffer $(10 \mathrm{mM}$ Tris- $\mathrm{HCl}$ pH 9.0, $60 \mathrm{mM} \mathrm{KCl}, 1.5 \mathrm{mM} \mathrm{MgCl}_{2}$ ), 2.0 units Taq DNApolymerase, $10 \mu \mathrm{M}$ of each primer, and $200 \mu \mathrm{M}$ dNTP. Oligonucleotide sequences were 5'ACT GGC ATG CTC CCC AGC GGA 3' and 3'GTG CCG TTA GTC TCT GAG GCG 5' primers for $\alpha$-calcineurin (resulting in a 214-pb product); 5'TTC ACA CAC GCA GTC GGT AT 3' and 3'CAT TCA GGG CTA AGG TCC AA 5' primers for leptin (resulting in a 366-pb product), accordingly to published sequences. Amplification conditions consisted of $1 \mathrm{~min}$ denaturation at $94^{\circ} \mathrm{C}, 1 \mathrm{~min}$ annealing at $60^{\circ} \mathrm{C}$, and $2 \mathrm{~min}$ 


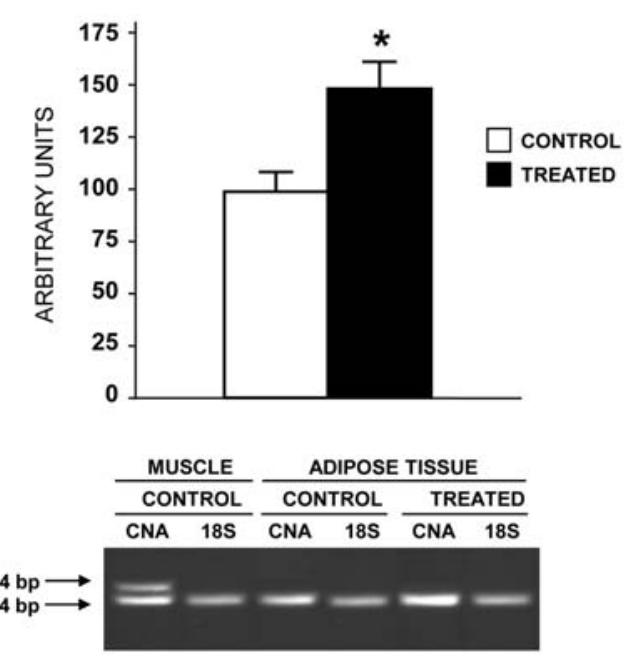

Figure 1. Calcineurin mRNA expression in adipose tissue of IL-15 chronicallytreated rats. The results presented are mean \pm SEM ( 7 animals per group). Statistical significance of results (Student's t test), ${ }^{*} \mathrm{p}<0.05$. Representative results of the RT-PCR methodology used. CNA, calcineurin; 18S, ribosomal $18 \mathrm{~S}$ subunit.

polymerization at $72^{\circ} \mathrm{C}$ for each step for 27 cycles for calcineurin and 35 cycles for leptin, and extension at $72^{\circ} \mathrm{C}$ for $7 \mathrm{~min}$. PCR products were electrophoresed on $2 \%$ agarose gels and visualized with ethidium bromide. A standard DNA ladder was used to estimate the length of each PCR product. Quantification was performed by densitometric analysis. Individual product bands and representative background were excised from each gel lane and analyzed by means of specific software (Phoretix). The results were normalized for the level of $18 \mathrm{~S}$ ribosomal subunit (5'CGC AGA ATT CCC ACT CCC GAC CC 3' and 3' CCC AAG CTC CAA CTA CGA GC $5^{\prime}$ primers (resulting in a 256 -pb product); denaturation $\left(95^{\circ} \mathrm{C}\right) 30 \mathrm{sec}$, annealing $\left(55^{\circ} \mathrm{C}\right) 1 \mathrm{~min}$, polymerization $\left(72^{\circ} \mathrm{C}\right)$ $2 \mathrm{~min}$, for 10 cycles, then extension $\left(72^{\circ} \mathrm{C}, 7 \mathrm{~min}\right)$.

Protein extraction and Western blotting. For protein extraction the cells were scraped in an ice cold buffer of $10 \mathrm{mM}$ Tris $\mathrm{pH} 7.5,10 \mathrm{mM}$ EDTA, $400 \mathrm{mM} \mathrm{NaCl}, 10 \%$ glycerol, $0.5 \%$ Nonidet P-40, $5 \mathrm{mM} \mathrm{NaF}$, and $0.01 \mathrm{mM}$ sodium orthovanadate, in the presence of protease inhibitors and then sonicated for $10 \mathrm{sec}$. After that, the samples were centrifugated at 13,000 rpm for $10 \mathrm{~min}$ and the supernatants were collected and protein concentrations were determined according to the method of BCA (Pierce, USA). Equal amounts of protein $(50 \mu \mathrm{g})$ were heat-denatured in sample-loading buffer $(50 \mathrm{mM}$ Tris- $\mathrm{HCl}$ pH 6.8, 100 mM DTT, 2\% SDS, 0.1\% bromophenol blue, $10 \%$ glycerol), resolved by SDS-polyacrylamide gel electrophoresis ( $8 \%$ polyacrylamide, $0.1 \%$ SDS) and transferred to Immobilon membranes (Immobilon PVDF, Millipore). The filters were blocked with PBS containing 5\% of BSA and incubated with polyclonal antibodies, anti- $\alpha$-calcineurin (Sigma) and antitubulin (Santa Cruz Biotechnology), which was used as an invariant control for the different studies. Donkey anti-mouse peroxidase-conjugated IgG (Jackson ImmunoResearch, Laboratories Inc., West Grove, USA) was used as secondary antibody. The membrane-bound immune complexes were detected by an enhanced chemiluminescence system (EZECL, Biological Industries, Israel).

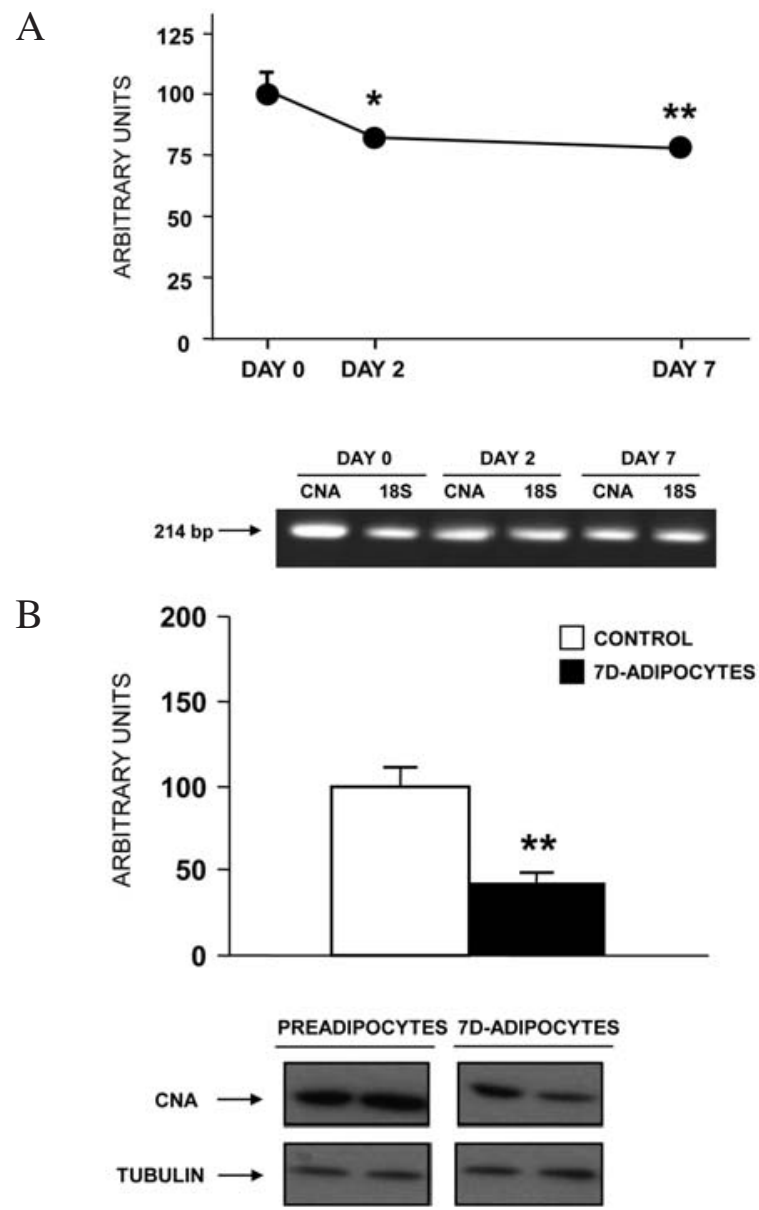

Figure 2. Regulation of calcineurin mRNA expression and protein content in 3T3-L1 adipocytes before and following induction of differentiation. The results presented are mean \pm SEM for 6 different wells. CNA, calcineurin $18 \mathrm{~S}$, ribosomal $18 \mathrm{~S}$ subunit. (A) Calcineurin mRNA expression following induction of differentiation, and representative results of the RT-PCR methodology used. Statistical significance of results (Student's t test), ${ }^{*} \mathrm{p}<0.05,{ }^{* *} \mathrm{p}<0.01$ (vs day 0 ). (B) Calcineurin protein content before (preadipocytes) and after (7d-adipocytes) the induction of differentiation, and representative results of Western blot. Statistical significance of results (Student's t test), ${ }^{* *} \mathrm{p}<0.01$ (vs preadipocyte group).

Statistical analysis. Statistical analysis of the data was performed by means of the Student's t test or oneway ANOVA.

\section{Results}

The results presented in Fig. 1 clearly show that treatment of animals with IL-15 for 7 days resulted in a significant increase $(43 \%)$ in calcineurin mRNA expression in WAT. Interestingly, it has to be remarked that only one band (corresponding to $214 \mathrm{bp}$ ) was present in adipose tissue, in contrast with what was found in skeletal muscle, where two bands corresponding to the different mRNA isoforms of the $\alpha$ subunit of calcineurin were detected (Fig. 1). Then we decided to analyze the modulation of $\alpha$-calcineurin mRNA expression during adipogenesis in the 3T3-L1 preadipose cell line. The results presented in Fig. 2 clearly show that, following induction of differentiation of preadipocytes to differentiated adipocytes, there was a significant decrease in $\alpha$-calcineurin mRNA levels (Fig. 2A). In addition, at day 7 of differentiation the $\alpha$-calcineurin protein content is also decreased (Fig. 2B). 
A

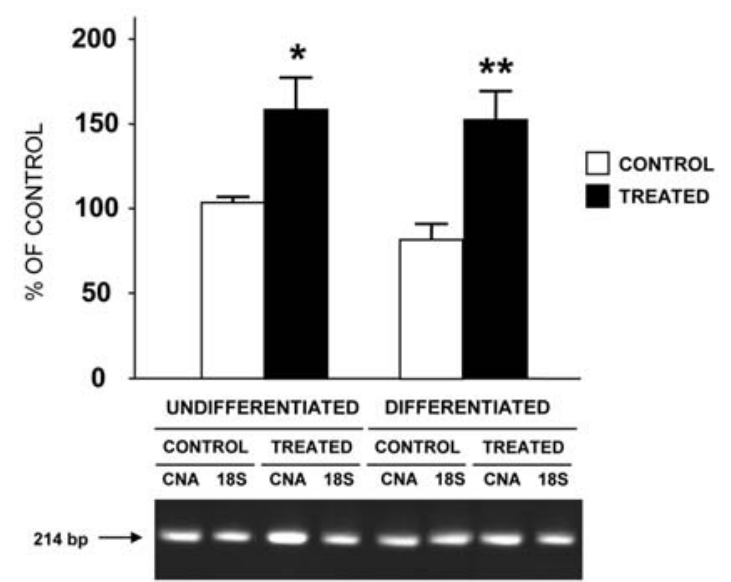

B

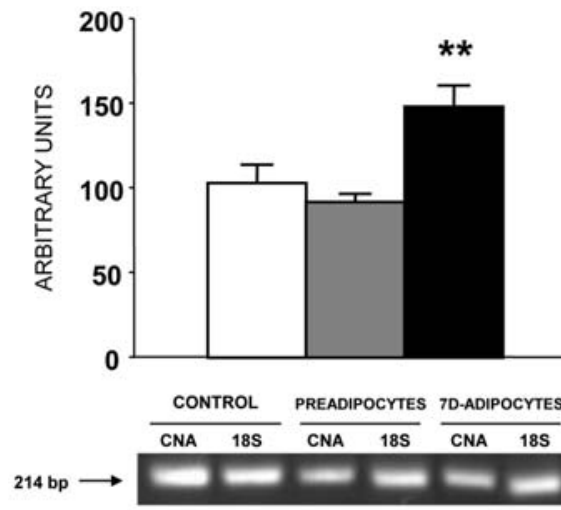

$\mathrm{C}$

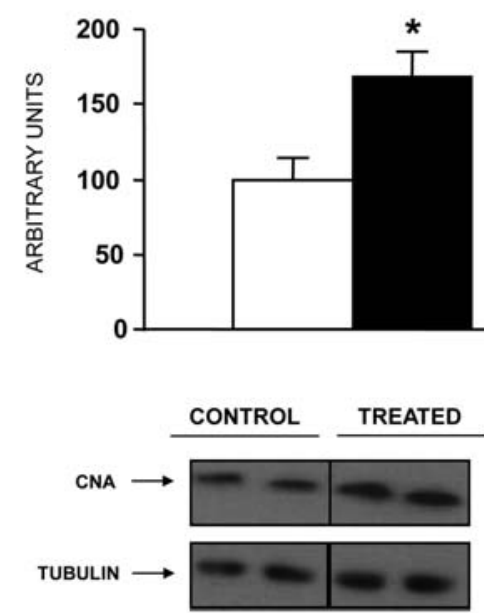

Figure 3. Effects of IL-15 on calcineurin mRNA expression and protein content in both undifferentiated and differentiated 3T3-L1 cells. The results presented are mean \pm SEM for 6 different wells. CNA, calcineurin; $18 \mathrm{~S}$, ribosomal $18 \mathrm{~S}$ subunit. (A) $48 \mathrm{~h}$ of $\mathrm{IL}-15$ treatment and representative results of the RT-PCR methodology used. Statistical significance of results (Student's ttest), ${ }^{*} \mathrm{p}<0.05,{ }^{* *} \mathrm{p}<0.01$ (vs non-treated group). (B) 7 days of IL-15 treatment, all groups were analyzed at day 7 after differentiation. Representative figure of the RT-PCR methodology used. Statistical significance of the results (Student's t test), ${ }^{* *} \mathrm{p}<0.01$ (vs day 0). (C) Calcineurin protein content before and after the induction of differentiation, and representative results of Western blot in a long-term study (7 days of IL-15 treatment). Statistical significance of the results (Student's t-test), ${ }^{*} \mathrm{p}<0.05$ (vs non-treated group).

In order to analyze the effects of IL-15 on $\alpha$-calcineurin levels, we performed both short- and long-term studies (see Materials and methods). In the short-term study, IL-15 induced a significant upregulation of $\alpha$-calcineurin mRNA expression in both preadipocytes and differentiating adipocytes (Fig. 3A). On the other hand, in the long-term study, only an increase in

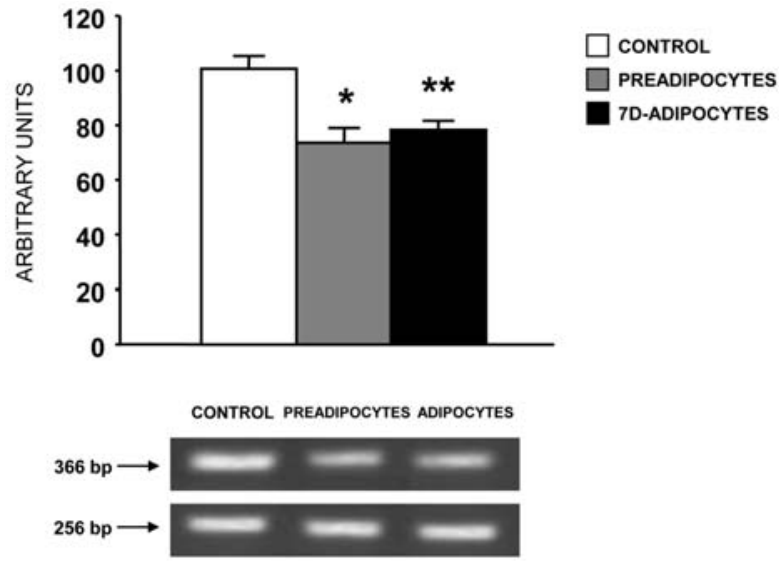

Figure 4. Effects of IL-15 treatment on leptin mRNA expression in both undifferentiated and differentiated 3T3-L1 cells during 7 days, and analyzed at day 7 after differentiation. The results presented are mean \pm SEM for 6 different experiments. Representative results of the RT-PCR methodology used. CNA, calcineurin; 18S, ribosomal 18S subunit. Statistical significance of results (Student's t test), ${ }^{*} \mathrm{p}<0.05, * * \mathrm{p}<0.01$ (vs day 0 ).

$\alpha$-calcineurin mRNA expression and protein content in 7d-adipocytes was observed (Fig. 3B and C).

It is accepted that the major part of expression changes needed to complete adipogenesis take place during the $48 \mathrm{~h}$ after the induction of differentiation (2). With the aim of confirming the effects of IL-15 on adipocyte differentiation, we examined leptin mRNA content in both $7 \mathrm{~d}$-adipocytes with 7-day treatment with IL-15 during the pre-differentiation period and also in 7d-adipocytes with 7-day treatment with IL-15 during post-differentiation period. Interestingly, the results presented in Fig. 4 show that the treatment with the cytokine decreased the leptin mRNA expression levels in both types of cells (26\% for preadipocytes and $22 \%$ for $7 d-$ adipocytes.

Finally, we decided to analyze the implication of calcineurin in the effects of IL-15 on adipogenesis. For this reason we treated cells with IL-15, FK506 (inhibitor of calcineurin activity) or both. As seen in Fig. 5, treatment with IL-15 for 7 days provoked a reduction of lipid content in 3T3-L1 cells which were differentiating (7d-adipocytes) as estimated by Red Oil $\mathrm{O}$ staining (Fig. 5A) and measured as diameter of lipid content of cells (Fig. 5B).

Moreover, the treatment with FK506 blocked the effects of IL-15 on lipid accumulation in the 3T3-L1cells.

\section{Discussion}

Intracellular $\mathrm{Ca}^{2+}$ seems to play a very important role in adipocyte differentiation as suggested by several studies $(6,7)$. In fact, an increase in $\mathrm{Ca}^{2+}$ concentrations during the earlier stages of adipogenesis both in human and 3T3-L1 adipocytes blocks the differentiating cellular process. Calcineurin, a $\mathrm{Ca}^{2+}$-dependent serine/threonine phosphatase, seems to be a key molecule in the regulation of the $\mathrm{Ca}^{2+}$ effects on adipocyte differentiation. Indeed, following an increase in intracellular $\mathrm{Ca}^{2+}$ there is an activation of calcineurin and a subsequent cascade of intracellular events that lead to a blockade of the differentiation process.

Bearing all this in mind, we decided to investigate the levels of $\alpha$-calcineurin in 3T3-L1 cells and their alterations during the 
A CONTROL

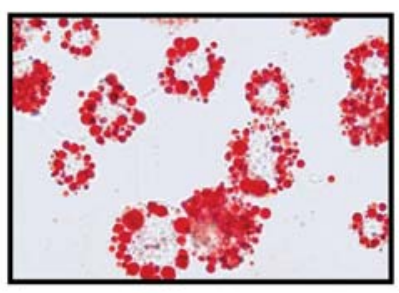

IL15

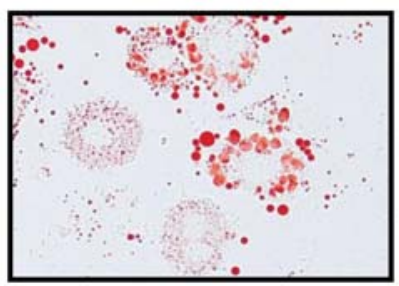

B

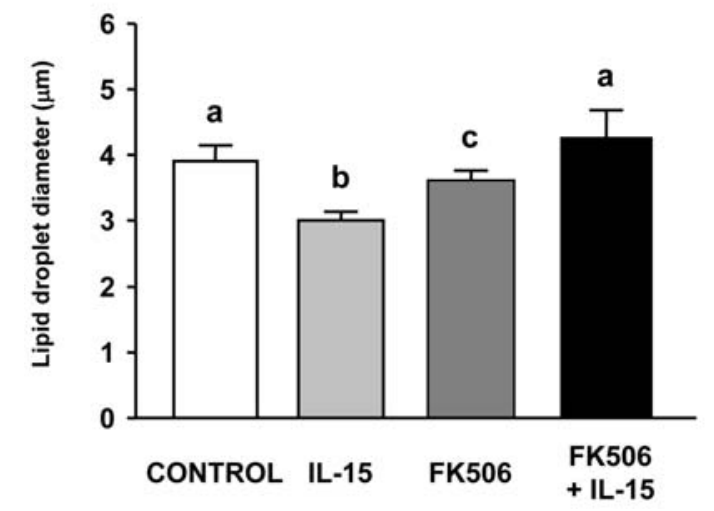

Figure 5. Red Oil O staining of both undifferentiated and differentiated 3T3-L1 cells after treatment with IL-15 and FK506.(A) Representative photographs of Red Oil O staining in 3T3-L1 cells which were differentiating ( 7 d-adipocytes) in a long-term study. (B) Diameter of lipid droplets measured by bright-field microscopy at $x 40(n=6)$. Statistical significance of the results by one-way analysis of variance (ANOVA). ns, non significant differences. Statistically significant difference by post-hoc Duncan test, different superscripts indicate differences between groups.

adipose differentiation process. For this reason, we analyzed both the mRNA and protein content at day 0 (preadipocytes) and following the induction of differentiation. There was a decrease $(21 \%)$ in $\alpha$-calcineurin mRNA levels during the differentiation process. This effect was also observed in the protein level in $7 \mathrm{~d}$-adipocytes, suggesting that the changes in $\alpha$-calcineurin mRNA and protein are associated with the differentiation process. These results agree with the proposed role of calcineurin as an inhibitor of adipocyte differentiation $(7,11)$. Therefore, a downregulation of calcineurin mRNA expression is necessary for a correct differentiation process. However, a persistent decreased level of calcineurin in 3T3-L1 may hamper the viability of differentiated cells since $\mathrm{Ca}^{2+}$ is essential for them. Indeed, intracellular $\mathrm{Ca}^{2+}$ has been described as necessary for lipogenesis in mature adipocytes (19).

IL-15 is a cytokine related to the maintenance and activation of different immune system cells $(12,13)$ but also with multiple functions outside it. Several studies have related this cytokine with protein metabolism both in vitro (20) and in vivo (15), demonstrating the anabolic effects of IL-15 on muscle tissue and cells. Interestingly, in the course of in vivo studies, it was observed that IL-15 treatment causes an important reduction in WAT mass, parallel to the effects on protein metabolism (16). These effects seem to be direct in adipose tissue (17), and are partially mediated by a lower uptake of triacylglycerols (16) and a reduction of lipogenesis (21). Additionally, it was mentioned that indirect mechanisms by which lipid deposition in WAT could be affected, like a decrease on intestinal lipid absorption (22) and changes in liver lipogenic rate, leading to lipoproteins with a lower content in triacylglycerols. Moreover, a direct effect of IL-15 on culture cells, where this cytokine causes an inhibition of lipid accumulation in the preadipose cell line 3T3-L1 has been described (18).

Taking into account the effects of IL-15 on lipid metabolism, we decided to analyze if the treatment with IL-15 causes any effect on calcineurin levels in adipose tissue, thus affecting the mechanism of adipose differentiation. Using the same experimental procedure previously described $(15,16)$, the treated animals presented an increased calcineurin mRNA expression in adipose tissue, suggesting that some of the effects of IL-15 on WAT were calcineurin mediated. In order to test this possibility, we decided to investigate the effects of IL-15 on both undifferentiated and adipocyte cells. The results obtained clearly indicate that the cytokine increases the expression of mRNA of calcineurin, suggesting that this protein mediates the effects of IL-15. In addition, we investigated the leptin mRNA content following the addition of the cytokine to 3T3-L1 cells, which decrease in both preadipocytes and $7 \mathrm{~d}$-adipocytes, supporting the role of IL-15 in the inhibition of adipogenesis. To confirm the hypothesis suggesting that IL-15 affects differentiation via calcineurin, we inhibit calcineurin activity during adipocyte diffentiation by using FK506 as previously decribed (7). The inhibition of calcineurin activity during adipogenesis did not affect lipid content in $7 \mathrm{~d}$ adipocytes; however, FK506 (a calcineurin inhibitor) abolished the inhibitory effect of IL-15 on lipid deposition in 3T3-L1 cultures.

Although further studies are necessary to confirm the calcineurin role in adipocyte differentiation, all these results allow us to suggest that the effects of IL-15 on adipocyte differentiation are partly mediated by calcineurin activity.

\section{Acknowledgements}

Gemma Fuster was supported from the Dirección General de Investigación Científica y Técnica (BFI2002-02186) of the Ministerio de Educación y Ciencia. Contract grant sponsor were Fondo de Investigaciones Sanitarias del Instituto de Salud Carlos III of the Ministerio de Sanidad y Consumo (contract grant number: 06/0907), Generalitat de Catalunya (SGR/00108), Ministerio de Ciencia y Tecnología (contract grant number: SAF 4744-2005).

\section{References}

1. Kim S and Moustaid-Moussa N: Secretory, endocrine and autocrine/paracrine function of the adipocyte. J Nutr 130: S3110-S3115, 2000.

2. Morrison RF and Farmer SR: Hormonal signaling and transcriptional control of adipocyte differentiation. J Nutr 130: S3116-S3121, 2000. 
3. Hausman DB, DiGirolamo M, Bartness TJ, Hausman GJ and Martin RJ: The biology of white adipocyte proliferation. Obes Rev 2: 239-254, 2001

4. Visscher TL and Seidell JC: The public health impact of obesity. Annu Rev Public Health 22: 355-375, 2001.

5. Popkin BM and Doak CM: The obesity epidemic is a worldwide phenomenon. Nutr Rev 56: 106-114, 1998.

6. Miller CW, Casimir DA and Ntambi JM: The mechanism of inhibition of 3T3-L1 preadipocyte differentiation by prostaglandin F2alpha. Endocrinology 137: 5641-5650, 1996.

7. Neal JW and Clipstone NA: Calcineurin mediates the calciumdependent inhibition of adipocyte differentiation in 3T3-L1 cells. J Biol Chem 277: 49776-49781, 2002.

8. Klee CB, Ren H and Wang X: Regulation of the calmodulinstimulated protein phosphatase, calcineurin. J Biol Chem 273 13367-13370, 1998.

9. Crabtree GR: Calcium, calcineurin, and the control of transcription J Biol Chem 276: 2313-2316, 2001.

10. Ho IC, Kim JH, Rooney JW, Spiegelman BM and Glimcher LH: A potential role for the nuclear factor of activated $\mathrm{T}$ cells family of transcriptional regulatory proteins in adipogenesis. Proc Natl Acad Sci USA 95: 15537-15541, 1998.

11. Neal JW and Clipstone NA: A constitutively active NFATc1 mutant induces a transformed phenotype in 3T3-L1 fibroblasts. J Biol Chem 278: 17246-17254, 2003.

12 Grabstein KH, Eisenman J, Shanebeck K, Rauch C, Srinivasan S, Fung V, Beers C, Richardson J, Schoenborn MA, Ahdieh M, et al: Cloning of a cell growth factor that interacts with the beta chain of the interleukin-2 receptor. Science 264: 965-968, 1994.

13. Burton JD, Bamford RN, Peters C, Grant AJ, Kurys G, Goldman CK, Brennan J, Roessler E and Waldmann TA: A lymphokine, provisionally designated as interleukin $\mathrm{T}$ and produced by a human adult T-cell leukemia line, stimulates T-cell proliferation and the induction of lymphokine-activated killer cells. Proc Natl Acad Sci USA 91: 4935-4939, 1994.
14. Giri JG, Ahdieh M, Eisenman J, Shanebeck K, Grabstein K, Kumaki S, Namen A, Park LS, Cosman D and Anderson D: Utilization of the beta and gamma chains of the IL-2 receptor by the novel cytokine IL-15. EMBO J 13: 2822-2830, 1994.

15. Carbo N, Lopez-Soriano J, Costelli P, Busquets S, Alvarez B, Baccino FM, Quinn LS, Lopez-Soriano FJ and Argiles JM: Interleukin-15 antagonizes muscle protein waste in tumourbeaing rats. Br J Cancer 83: 526-531, 2000.

16. Carbo N, Lopez-Soriano J, Costelli P, Alvarez B, Busquets S, Baccino FM, Quinn LS, Lopez-Soriano FJ and Argiles JM: Interleukin-15 mediates reciprocal regulation of adipose tissue and muscle mass: a potential role in body weight control. Biochim Biophys Acta 1526: 17-24, 2001.

17. Alvarez B, Carbo N, Lopez-Soriano J, Drivdahl RH, Busquets S, Lopez-Soriano FJ, Argiles JM and Quinn LS: Effects of interleukin-15 (IL-15) on adipose tissue mass in rodents obesity models: evidence for direct IL-15 action on adipose tissue. Biochim Biophys Acta 1570: 33-37, 2002.

18. Quinn LS, Strait-Bodey L, Anderson BG, Argiles JM and Havel PJ: Interleukin-15 stimulates adiponectin secretion by 3T3-L1 adipocytes: evidence for a skeletal muscle-to-fat signaling pathway. Cell Biol Int 29: 449-457, 2005.

19. Zemel MB: Mechanisms of dairy modulation of adiposity. J Nutr 133: S252-S256, 2003.

20. Quinn LS, Anderson BG, Drivdahl RH, Alvarez B and Argiles JM: Overexpression of interleukin-15 induces skeletal muscle hypertrophy in vitro: implications for treatment of muscle wasting disorders. Exp Cell Res 280: 55-63, 2002.

21. Lopez-Soriano J, Carbo N, Almendro V, Figueras M, Ribas V, Busquets S, Lopez-Soriano FJ and Argiles JM: Rat liver lipogenesis is modulated by interleukin-15. Int J Mol Med 13: 817-819, 2004.

22. Almendro V, Carbo N, Busquets S, Lopez-Soriano J, Figueras M, Ametller E, Argiles JM and Lopez-Soriano FJ: Interleukin-15 decreases lipid intestinal absorption. Int J Mol Med 15: 963-967, 2005. 